\title{
O USO DE PEIXES COMO BIOINDICADOR AMBIENTAL EM ÁREAS DE VÁRZEA DA BACIA AMAZÔNICA
}

\author{
Carlos Edwar C. Freitas \& Flávia K. Siqueira-Souza; Departamento de Ciências Pesqueiras \\ Universidade Federal do Amazonas - Av. Gen. Rodrigo Otávio, 3000. Manaus - Amazonas. 69077-000 \\ Email para correspondência: cefreitas@ufam.edu.br
}

\section{RESUMO}

O uso de bioindicadores pode constituir uma importante ferramenta para monitoramento ambiental, e para ecossistemas aquáticos o uso de espécies de peixes é bastante eficiente, pois são componentes comuns e de fácil amostragem, bem como podem apresentar diferentes estilos de vida e habitats durante seu ciclo de vida. Neste artigo utilizamos como critérios para a seleção das espécies indicadoras, as seguintes características: ser taxonomicamente bem definido e facilmente reconhecível por não-especialistas, apresentar distribuição geográfica ampla, ser abundante ou de fácil coleta, preferencialmente possuir tamanho médio/grande, apresentar baixa mobilidade e longo ciclo de vida, dispor de características ecológicas conhecidas e ter possibilidade de uso em estudos em laboratório. Desta forma, indicamos oito espécies de peixes típicos das várzeas amazônicas: Pellona castelneana, Potamorhina altamazonica, Prochilodus nigricans, Mylossoma duriventre, Pygocentrus nattereri, Serrasalmus rhombeus, Triportheus angulatus e Liposarcus pardalis, para uso como bioindicadores em programas de monitoramento ou de avaliação de alterações ambientais.

\section{INTRODUÇÃO}

O termo "bioindicadores" pode ser definido como a escolha de espécies dada sua sensibilidade ou tolerância a diversos tipos de alterações ambientais, geralmente causadas por ações antropogênicas, como poluição orgânica, assoreamento, construção de barragens, pesca predatória entre outros (Washington, 1984, Agostinho et al., 2005). Os indicadores biológicos são muito úteis por sua especificidade em relação a certos tipos de impacto, já que inúmeras espécies são comprovadamente sensíveis a um tipo de poluente e mais tolerantes a outros (Washington, 1984). Assim índices podem ser criados especificamente, conforme o tipo de impacto ambinetal, para se detectar derramamento de óleo, poluição orgânica, alteração de pH e oxigênio na água, lançamento de pesticidas, entre outros fatores (Buss et al., 2003).

De forma geral, quanto mais rápido for a identificação de fatores que propiciem condições adversas ao ambiente, maior será as chances de mitigação deste impacto aos níveis superiores da organização biológica como comunidades e ecossistemas (Arias et al., 2007) (Figura 01)

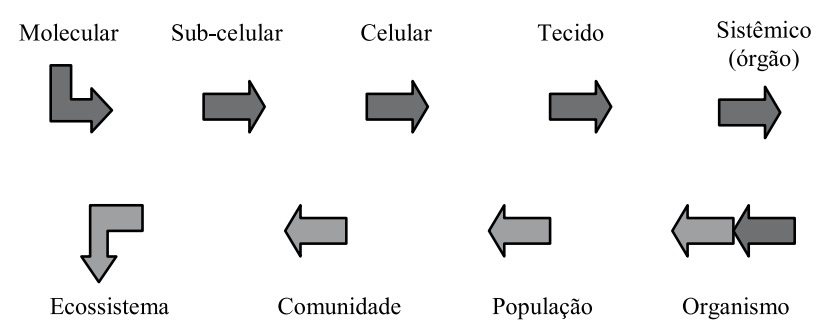

Figura 01 - Representação esquemática da organização biológica durante um tipo de impacto negativo no ambiente (adaptado de Arias et al., 2007). 
O termo "resposta biológica" se refere ao conjunto de reações de um indivíduo ou de uma comunidade em relação a um estímulo ou a um conjunto de estímulos (Armitage, 1995). Por estímulo, podemos entender uma ação (fator) que gere algum tipo de reação no indivíduo, que possa ser refletido ou medido na população ou na comunidade (Buss et al., 2003).

Os peixes são um componente comum e familiar nos ecossistemas aquáticos, sendo vistos como excelentes indicadores das condições ambientais, uma vez que podem refletir os distúrbios em diversas escalas, devido às suas características de mobilidade, estilo de vida e por sua posição próxima do topo da cadeia alimentar.

A biodiversidade, representada pela riqueza e abundância de espécies, por números/índices ou por modelos ecológicos, assim como os fatores e interação de fatores que a determinam, tem sido objeto de muitos estudos, principalmente nesta época em que os impactos antrópicos resultam na extinção de inúmeras espécies antes mesmo que elas sejam descritas pela Ciência (Freitas et al., 2007).

De acordo com Karr (1981), Ramelow et al. (1989) e Schulz \& Martins-Junior (2001) os peixes são excelentes ferramentas no monitoramento de ambientes aquáticos, servindo como importantes bioindicadores, pois respondem de várias maneiras à contaminação, como por exemplo, mudanças na taxa de crescimento e na maturação sexual. Modificações na estrutura da comunidade de peixes, tais como a abundância e diversidade de espécies, também podem refletir os efeitos de vários estressores da integridade biótica do rio como um todo (Fausch et al., 1990).

A comunidade de peixes inclui uma variedade de espécies e níveis tróficos que seguramente pode ter reflexo no grau do distúrbio ambiental. Algumas espécies de peixes são mais sensíveis a alterações nas características químicas e físicas da água, tais como $\mathrm{pH}$ ou oxigênio dissolvido, as quais podem ser causadas por perturbações ambientais como revolvimento do sedimento de fundo de lagos e igarapés; contaminação por vários tipos de poluentes orgânicos ou inorgânicos, variações naturais, dentre outros fatores. Comparados com outros grupos, como invertebrados, os peixes podem fornecer uma quantidade maior de informações, além de serem facilmente capturáveis e identificáveis.

Os distúrbios do ambiente podem ser refletidos nos peixes por meio de diferentes respostas nos diversos níveis da organização biológica, respostas estas que variam de acordo com o grau de plasticidade fenotípica que cada grupo de peixes possui. Esta plasticidade fenotípica (ou somática) pode ser definida como os limites da variação morfológica e fisiológica na expressão de um dado genótipo quando exposto a mudança nas condições ambientais.

O uso de peixes como ferramenta no monitoramento biológico assume extrema importância na Amazônia, uma vez que, nesta região, o consumo de peixes pela população, principalmente a ribeirinha, é muito alto, chegando a $454 \mathrm{~g} /$ dia por pessoa (Ruffino, 1999). Como os peixes são bioacumuladores, o constante monitoramento em áreas de risco é fundamental para que não ocorra contaminação da população humana.

\section{MATERIAL E MÉTODOS}

Durante os últimos seis anos, diversos pesquisadores, dentre estes os autores deste artigo, participaram da elaboração e realização de Estudos de Impactos Ambientais/EIA e Relatório de Impacto Ambiental/RIMA no estado do Amazonas, tais como o Gasoduto CoariManaus, a recuperação da Rodovia BR-319 e o Gasoduto Juruá-Urucu, empreendimentos de médio e grande porte (os dois últimos citados, ainda estão em processo de licenciamento pelo Instituto Brasileiro do Meio Ambiente e dos 
Recursos Naturais - IBAMA e pelo Instituto de Proteção Ambiental do Amazonas - IPAAM), de forma que diversos grupos bióticos da fauna e flora puderam ser identificados e evidenciados nos diferentes ambientes avaliados nos estudos.

Paralelo a realização de tais estudos, um projeto de pesquisa de longa duração e grande relevância Nacional e Internacional denominado Inteligência Socioambiental Estratégica da Indústria do Petróleo na Amazônia PIATAM, que teve início em 2001 e se estende até o presente, também propiciou a pesquisa de componentes bióticos no que tange as questões ambientais em ambientes de várzea.

Como o elemento objeto deste artigo é a ictiofauna como indicador ambiental, foi realizado um levantamento minucioso com base nas séries históricas obtidas dos EIA mencionados e as provenientes das pescarias experimentais realizadas no âmbito do Projeto Piatam, de forma a se ter grande informações sobre a riqueza e abundância dos peixes das várzeas amazônicas que norteassem a composição deste estudo.

Neste sentido, apresentamos uma proposta de espécies de peixes bioindicadoras, usando como base os critérios propostos por Johnson et al. (1993), que estabeleceram que um indicador biológico "ideal" deve possuir as seguintes características:

- ser taxonomicamente bem definido e facilmente reconhecível por não-especialistas;

- apresentar distribuição geográfica ampla;

- ser abundante ou de fácil coleta;

- preferencialmente possuir tamanho grande;

- apresentar baixa mobilidade e longo ciclo de vida;

- dispor de características ecológicas bem conhecidas e;

- ter possibilidade de uso em estudos em laboratório.

\section{RESULTADOS}

A partir dos critérios anteriormente listados, consideramos que as espécies que podem ser indicadas como bioindicadoras são: Pellona castelneana, Potamorhina altamazonica, Prochilodus nigricans, Mylossoma duriventre, Pygocentrus nattereri, Serrasalmus rhombeus, Triportheus angulatus e Liposarcus pardalis.

Uma breve descrição da ecologia destas espécies, a partir de Soares et al. (2007) é fornecida a seguir:

Nome Científico: Pellona castelnaeana (Valenciennes, 1847)

Nome comum: apapá amarelo, sardinhão

Informações ecológicas: apapá amarelo é pelágico, habita os paranás, lagos e rios de águas brancas, claras e pretas. Nos lagos pode ser capturado na floresta alagada e na água aberta durante os períodos diurno e noturno. É piscívoro, alimenta-se principalmente de pequenos Characiformes e Perciformes, mas, os camarões e os invertebrados aquáticos podem fazer parte da dieta. Espécie de hábitos noturnos, migradora, desova total e fecundação externa. A reprodução ocorre entre a seca (novembro) e enchente (abril). As fêmeas iniciam o processo de maturação sexual aos $32 \mathrm{~cm}$ de comprimento padrão.

Nome científico: Potamorhina altamazonica (Cope, 1878)

Nome comum: branquinha-cabeça-lisa Informações ecológicas: branquinha-cabeçalisa é bentopelágica, habita as margens de lagos e rios de água branca e preta. Nos lagos pode ser capturada na floresta alagada e na água aberta, principalmente durante o dia. É iliófaga, possui dieta constituída de matéria orgânica, algas e microorganismos que vivem na lama. $\mathrm{O}$ estômago adaptado a esse tipo de alimentação tem paredes musculosas em forma de moela e um intestino longo e enovela- 
do. Os jovens também podem são capturados na vegetação aquática. Espécie de hábitos diurnos, desova total, migradora, fecundação externa, que na época de reprodução forma grandes cardumes para desovar rio acima em ambientes de águas brancas. A reprodução ocorre provavelmente, durante a enchente. As fêmeas iniciam processo de maturação sexual aos $13,7 \mathrm{~cm}$.

Nome Científico: Prochilodus nigricans (Agassiz, 1829)

Nome comum: curimatã

Informações ecológicas: curimatã é bentopelágica, habita os paranás, lagos e rios de águas brancas, claras e pretas. Nos lagos pode ser capturada na floresta alagada e na água aberta, em ambos os períodos, diurno e noturno. É detritívora, alimenta-se de detritos, material amorfo de material orgânico ou litter associados com o sedimento, microflora (bactérias e fungos) e ocasionamente, invertebrados aquáticos. Espécie de hábitos diurnos, migradora, desova total, fecundação externa, que na vazante forma grandes cardumes que se deslocam em direção ao encontro dos rios de águas brancas e pretas para desovar. Depois da desova retornam as áreas alagadas para se alimentar. A reprodução ocorre do final da seca (dezembro) a início da enchente (janeiro a março). As fêmeas iniciam o processo de maturação sexual aos $26,2 \mathrm{~cm}$ de comprimento padrão. Sobrevive em ambientes com baixas concentrações de oxigênio por meio da respiração na superfície aquática (ASR).

\section{Nome científico: Mylossoma duriventre} (Cuvier, 1817)

Nome comum: pacu-comum, pacu-manteiga. Informações ecológicas: pacu-comum é pelágico, habita lagos de rios de águas brancas, claras e pretas. Nos lagos os adultos são capturados na água aberta e na floresta alagada ao passo que os jovens na vegetação aquática. É onívoro, mas há variações ontogênicas na alimentação. Os adultos alimentam-se principalmente de frutos e sementes das florestas de várzea alagadas, folhas e de invertebrados terrestres e aquáticos. Os juvenis têm preferência por capins, gramíneas e moluscos. Espécie de hábitos diurnos, migradora, desova total, fecundação externa, que na vazante forma cardume junto com Mylossoma aureum e migra rio acima para desovar nas confluências de rios de águas pretas com rios de águas brancas. $\mathrm{O}$ período de reprodução é longo, abrange a seca (novembro) e a cheia (maio), sendo a desova mais intensa entre dezembro e fevereiro. As fêmeas iniciam o processo de maturação sexual aos $15,5 \mathrm{~cm}$ e os machos aos $14,8 \mathrm{~cm}$ de comprimento total, a fecundidade varia de 25.000 a 100.000 ovócitos. Sobrevive em ambientes com baixas concentrações de oxigênio por meio da respiração na superfície aquática (ASR) e que após longo tempo de exposição ocorre a expansão do lábio da mandíbula inferior denominada localmente de "uaiu".

Nome científico: Pygocentrus nattereri (Kner, 1860)

Nome comum: piranha-vermelha, piranhacaju

Informações ecológicas: piranha-caju é pelágica, habita os lagos e remansos de rio de águas brancas, águas claras e pretas com baixa correnteza. Nos lagos são capturadas principalmente na água aberta em ambos os períodos, diurno e noturno. É piscívora e tem amplo espectro alimentar. Ingere principalmente peixes, arrancando pedaços por meio de mordidas, e ocasionalmente artrópodes terrestres, crustáceos e material vegetal, além de escamas e nadadeiras. Os adultos alimentam-se principalmente ao anoitecer e alvorecer enquanto os jovens são ativos durante o dia. Espécie de hábitos diurnos, sedentária, desova parcelada, fecundação externa. A reprodução ocorre entre o final da seca (dezembro) e a enchente (abril). As fêmeas atingem o processo de maturação sexual aos $13 \mathrm{~cm}$ e a fecundidade é varia en- 
tre 2768 a 27711 ovócitos que são dispersos entre vegetação aquática e galhadas no lago. $\mathrm{O}$ casal protege a prole. Na época de águas baixas (seca), forma pequenos cardumes que ficam confinados dentro dos lagos, podendo se tornar agressiva e potencialmente perigosa, uma vez que sua dentição pode infligir terríveis mordidas.

Nome científico: Serrasalmus rhombeus (Linnaeus, 1766)

Nome comum: piranha-preta, piranha

Informações ecológicas: piranha-preta é bentopelágica, habita os lagos e rios de águas brancas, claras e pretas, sendo mais abundante nos rios pobres em nutrientes, como o rio Negro. Nos lagos os adultos são capturados principalmente na água aberta ao passo que os alevinos e jovens ocorrem na vegetação aquática peixes. É piscívora, mas pode ocasionalmente ingerir insetos, camarões, frutos, sementes e material vegetal. Os jovens consomem nadadeiras de outros peixes, insetos aquáticos e microcrustáceos. Espécie de hábitos diurnos, sedentária, desova parcelada, fecundação externa, que desova em ambientes lênticos, nas raízes de vegetação aquática. A reprodução ocorre durante longo período, com dois picos de desova, na cheia (junho) e final de seca (dezembro). As fêmeas iniciam o processo de maturação sexual entre 16,0 a $17,9 \mathrm{~cm}$ e os machos e 14,0 a $15,9 \mathrm{~cm}$ de comprimento total. A fecundidade média total é de 4303 ovócitos. Esta espécie cuida da prole, sendo o casal que protege os alevinos por cerca de três semanas.

Nome científico: Triportheus angulatus (Spix \& Agassiz, 1829)

Nome comum: sardinha-papuda

Informações ecológicas: sardinha-papuda é pelágica, abundante nos lagos e rios de águas brancas, claras e pretas. Nos lagos de água branca, os adultos são capturados na água aberta e na floresta alagada ao passo que os jovens na vegetação aquática. É onívora, adaptada a se alimentar de frutos/sementes e invertebrados da floresta alagada que caem na superfície da água. Espécie de hábitos diurnos, migradora, desova total, fecundação externa, que na vazante forma cardumes e se deslocam em direção às águas turvas dos rios de água branca para desovar. Depois da desova retornam as áreas alagadas para se alimentar. A reprodução ocorre no final da seca (dezembro) e início da enchente (fevereiro), coincidindo com o período de chuvas. As fêmeas iniciam o processo de maturação sexual aos $13 \mathrm{~cm}$ de comprimento padrão e a fecundidade total varia entre 17450 e 32030 ovócitos. Sobrevive em ambientes com baixas concentrações de oxigênio por meio da respiração na superfície aquática (ASR) e após longo tempo ocorre a expansão do lábio da mandíbula inferior denominada localmente de "uaiu". Durante respiração na superfície aquática a sardinha projeta as barbelas que auxiliam na aeração das brânquias.

Nome científico: Liposarcus pardalis (CasteInau, 1855)

Nome comum: bodó, acari-bodó

Informações ecológicas: acari-bodó é bentônico, habita os lagos e rios de águas brancas, claras e pretas. Nos lagos ocorre na vegetação aquática e na floresta alagada. É detritívora, alimenta-se de material orgânico amorfo, sedimentos e algas. Espécie de hábitos diurnos e noturnos, sedentária, desova total, fecundação externa, que no período reprodutivo constrói ninhos em tocas no fundo ou nos barrancos de rios e lagos. A reprodução ocorre entre a seca (agosto) e meados de enchente (maio). As fêmeas iniciam o processo de maturação sexual aos 24 e os machos aos $27 \mathrm{~cm}$ de comprimento padrão. A fecundidade total varia entre 856 a 1964 ovócitos. Sobrevive em ambientes com baixas concentrações de oxigênio utilizando o estômago como órgão acessório para a respiração aérea. 


\section{DISCUSSÃO}

Segundo Lowe-McConnell (1999) a ictiofauna da Região Neotropical é caracterizada por uma leve dominância de Characiformes sobre Siluriformes, com pequena representação de outros grupos. Entretanto, resultados de pesquisas nas várzeas amazônicas indicam que essa dominância é realmente mais evidenciada (Siqueira-Souza \& Freitas, 2004; Sousa \& Freitas, 2008).

Esta dominância de Characiformes, observada também nas amostragens realizadas nos estudos de avaliação de impactos ambientais, traduziu-se na indicação de seis espécies desta ordem: Potamorhina altamazonica, Prochilodus nigricans, Mylossoma duriventre, Pygocentrus nattereri, Serrasalmus rhombeus e Triportheus angulatus como bioindicadores, pois atenderiam aos critérios de distribuição geográfica ampla e abundância.

A única representante de Clupeiformes incluída na lista de bioindicadores proposta foi Pellona castelneana que também atende aos critérios mencionados e apresenta tamanho relativamente grande, além de ciclo de vida longo.

Além da grande abundância nas várzeas e do ciclo de vida longo, um outro aspecto positivo de Liposarcus pardalis como bioindicador é sua baixa mobilidade, uma vez que não realiza migrações.

Dois aspectos não considerados por Johnson et al. (1993) são: 1) a vantagem de apresentar bioindicadores de diferentes níveis tróficos, pois este procedimento pode assegurar a detecção de alterações ambientais de diferentes escalas de intensidade. Peixes planctófagos, que filtram a coluna d'água, podem ter uma resposta biológica mais rápida, principalmente para poluentes que interfiram no processo de absorção do oxigênio pelas brânquias. Por outro lado, predadores do topo da cadeia alimentar podem desenvolver processos de bioacumulação de poluentes que se en- contram em baixas concentrações no ambiente aquáticos e 2) o fato das espécies selecionadas apresentarem grande importância na atividade de pesca na região, sendo itens importantes na dieta alimentar dos moradores ribeirinhos/ citadinos que alimentam-se principalmente de peixe ao longo do ano e como tal a seleção das espécies também apresenta, neste sentido, um fator social/econômico no resultado.

É importante mencionar que a lista das oito espécies apresentadas, é uma indicação para trabalhos de monitoramento em ambientes de várzea da Amazônia, uma vez que características específicas do ambiente, que pode sofrer algum tipo de impactado, podem determinar a necessidade de se optar por outras espécies.

\section{AGRADECIMENTOS}

Os autores agradecem ao Projeto PIATAM, financiado com recursos FINEP/PETROBRAS, além do Departamento Nacional de Infraestrutura de Transportes - DNIT e da Petrobras pelo suporte financeiro aos EIAs.

\section{REFERÊNCIAS BIBLIOGRÁFICAS}

AGOSTINHO, A.A.; THOMAZ, S.M. \& GOMES, L.C. Conservação da biodiversidade em águas continentais do Brasil. Megadiversidade, v.1, n.1. 70 - 78, 2005.

ARIAS, A.R.L; BUSS, D.F.; ALBUQUERQUE, C.; INÁCIO A.F.; FREIRE, M.M.; EGLER, M. Utilização de bioindicadores na avaliação de impacto e no monitoramento da contaminação de rios e córregos por agrotóxicos. Ciência, saúde coletiva, Rio de Janeiro, v.12, n.1, 61-72, 2007.

ARMITAGE, P.D. Behavior and ecology of adults, p.194-224. In: The chironomidae: biology and ecology of non-biting midges. ARMITAGE, P.D.; CRASNTON, P.S. \& 
L.C.V. PINDLER, [Eds.], London: Chapman \& Hall. 1995.

BUSS, D.F.; BAPTISTA, D.F.; NESSIMIAN, J.L. Bases conceituais para a aplicação de biomonitoramento em programas de avaliação da qualidade da água de rios. Cadernos de Saúde Pública, Rio de Janeiro. v.19, n.2, p.465-473. 2003.

FAUSCH, K.D. LYONS, J. KARR, J.R. \& ANGERMEIER, P.L. Fish communities as indicators of environmental degradation, p.123124. In: Biological indicators of stress in fish. ADAMS, S.M. [ed] American Fisheries Society, Symposium 8., American Fisheries Sociey. Bethersda, Maryland. 1990.

FREITAS, C.E.C.; SOARES, M.G.M.; SIQUEIRA-SOUZA, F.K.; COSTA, E.L. Indicadores Biológicos da Ictiofauna, p.77-85. In: CAVALCANTE, K.V.; RIVAS, A.A.F.; FREITAS, C.E.C. [Org.] Indicadores Socioambientais e atributos de referência para 0 trecho Urucu-Coari-Manaus, rio Solimões, Amazônia Ocidental. Manaus, EDUA, 2007.

JOHNSON, R.D.; WIEDERHOLM, T. \& ROSEMBERG, D.M. Freshwater biomonitoring using individual organisms, populations, and species assemblages of benthic macroinvertebrates, p.40-158. In: Freshwater Biomonitoring and Benthic Macroinvertebrates. ROSENBERG, D.M.; RESH, V.H. [eds] New York, Chapman \& Hall, 1993.

KARR, J.R. Assessment of biotic integrity using fish communities. Fisheries, v.6, p.2127, 1981.

LOWE-MCCONNELL, R. Estudos ecológicos em comunidades de peixes tropicais. EDUSP. São Paulo-SP, 1999. 524p.
RAMELOW, G.J.; WEBRE, C.L.; MUELLER, C.L.; BECK, J.N; YOUNG, J.C.; LANGLEY, M.P. Variations of heavy metals and arsenic in fish and other organisms from the Calcasien River and Lake, Louisiana. Archives of Environmental Contamination Toxicology, v.18, p.804-818, 1989.

RUFFINO, M.L. Fisheries Development in the lower Amazon River, p.101-111. In: Varzea diversity, development and conservation of Amazonia's whitewater floodpains RADOCH, C.; AYRES, J.N.; PINEDO-VASQUEZ, M.; HENDERSON, A. [Eds.]. The New York Botanical Garden Press. New York. 1999.

SCHULZ, U.H. \& MARTINS-JUNIOR, H. Astyanax fasciatus as bioindicator of water pollution of Rio dos Sinos, RS, Brasil. Brazilian Journal Biology, v.61, n.4, p.1-8, 2001.

SIQUEIRA-SOUZA, F.K. \& FREITAS, C.E.C. Fish diversity of floodplain lakes on the lower stretch of the Solimões River. Brazilian Journal of Biology, v.64, n.3, p.1-10, 2004.

SOARES, M.G.M.; COSTA, E.L.; SIQUEIRA-SOUZA, F.K.; ANJOS, H.D.B.; YAMAMOTO, K. C.; FREITAS, C.E.C. Peixes de lagos do Médio Rio Solimões. Manaus. Editora da Universidade do Amazonas - EDUA, 2007, 172p.

SOUSA, R.G.C. \& FREITAS, C.E.C. 2008. The influence of flood pulse on fish communities of floodplain canals in the Middle Solimões River. Neotropical Ichthyology, v.6, n.2, p.249-255, 2008.

WASHINGTON, H.G. Diversity, biotic and similarity índices. A review with special relevance to aquatic ecosystems. Water Research, v.18, p.653-694, 1984. 